work in community-based HIV education for gay men, and confidently regards the Terrence Higgins Trust as a gay organisation - a description which the THT has consistently rejected since the mid-1980s. There is no sense here at all of AIDS as an issue of the greatest urgency, or of the extraordinary difficulties that have continuously faced those trying to develop effective and humane education in Britain for the constituency which continues to make up $80 \%$ of the AIDS mortality figures. AIDS and the Public Debate would thus have been a stronger book had the commissioning editors attempted to balance articles by US medical scientists with voices from American nongovernment community organisations, rather than an arbitrary coda of non-Americans, whose work adds little to our understanding of AIDS outside the USA, and tends to blur the focus of an otherwise valuable anthology.

SIMON WATNEY

The Red Hot AIDS Charitable Trust, Suite 32, The Eurowide Centre, 49 Effra Road, Brixton, London SW2 1B2

\section{Nursing Ethics. A Principle-based Approach}

\author{
Steven D Edwards, London, \\ Macmillan Press Ltd, 1996, 183 \\ pages, £11.99.
}

The intention stated by Steven Edwards is to produce a text on a principle-based approach to nursing ethics, comparable to the standard text on medical ethics by Beauchamp and Childress, ${ }^{1}$ which is less dense and therefore more accessible to students of ethics. He has succeeded admirably in these aims.

The approach, the principles themselves, and potential conflicts, as detailed by Beauchamp and Childress, are discussed. The text is well written; the discussion is lucid and orderly, rendering the work accessible to those with no previous knowledge of ethics. Arguments are clearly laid out, with easily identifiable premises and logical conclusions. In this regard, the text would be very useful to students learning the use of argument in health care ethics.
Although the author uses scenarios specific to nursing, many of these would be very familiar to junior medical staff - patients refusing treatment, the demands of the service requiring unpaid extra work, violence from patients and so on.

The contemporary challenges to "principle-ism" in nursing ethics have been summarised, the author concentrating on the approach developed from the work of Gilligan and Noddings, loosely referred to as a "care-based" approach. It is not entirely clear from the text that this challenge is not confined to nursing: there has been considerable debate about the merits of a principle-based approach over the past few years, the entire issue of the April 1990 fournal of Medicine and Philosophy providing a contemporary critique of bioethics. Clouser and Gert $^{2}$ (cited in the bibliography of the textbook) in this issue argue that "principles", as they are currently applied, serve purely as checklists of unrelated considerations, with no unifying theory within which to ground and relate these. To my mind, this is a serious charge against principle-ism, which any defence needs to acknowledge and take account of. It may be that the author felt this inappropriate to the target audience, but a brief outline of the wider context of this debate would have been helpful.

Additionally, Gilligan's thinking appears to have been misrepresented. Gilligan is said to have identified a focus on care in the moral thinking of females, "distinct from, and superior to, an allegedly male mode of thinking. ..." (page 132). My own understanding is that Gilligan ${ }^{3}$ herself claims that it is distinct, but not superior - mature individuals need to consider the voices of both care and justice. Neither does she claim that the care focus is exclusive to the thinking of females.

These reservations aside, the discussion of the care-based challenge as described here is thoughtful and well argued, the author concluding that principles can be applied in a manner which is "infused with care" (page 155). Further, in upholding a commitment to the primacy of the principles, he does not shrink from pointing out that there may be costs involved in so doing.

The author concludes the work by using the principle-based approach to consider the questions "what actions can be described as supererogatory", and "are nurses required to perform these". This is, I think, the first time I have seen this issue treated in this way in nursing ethics writing, and the discussion is timely in the light of the current climate within the UK health service. Again, much of the discussion would be meaningful to other health care professionals.

Overall, this is very worthwhile book to have on hand for those involved in teaching ethics to health care professionals, and a particularly useful textbook for students of nursing ethics.

\section{References}

1 Beauchamp TL, Childress JF. Principles of biomedical ethics [3rd ed]. Oxford: Oxford University Press, 1989.

2 Clouser KD, Gert B. A critique of principleism. Fournal of Medicine and Philosophy 1990; 15: 219-36.

3 Gilligan C. In a different voice: psychological theory and women's development. Cambridge, Mass: Harvard University Press, 1982.

JEAN HARBISON Department of Health and Nursing, Queen Margaret College, Edinburgh

\section{Of Life and Death. An Australian Guide to Catholic Bioethics}

\author{
Elizabeth Hepburn, North \\ Blackburn, Harper Collins \\ Publishers, 1996, 234 pages, \\ A $\$ 22.95$.
}

Dr Elizabeth Hepburn makes it clear in the preface to this book that readers need no specialist theological or philosophical studies, since it is not meant to be a comprehensive or scholarly work. It is, however, a valuable manual and a resource book of substance for teachers and nurse educators who would like to know the teaching of the Catholic Church on a wide range of controversial life and death issues in a reader-friendly form. The bulk of the book represents a development from lecture notes on ten biomedical topics given to student nurses.

Part one of the book begins with a brief and clear account of the main moral principles used for decisionmaking in biomedical ethics - justice, autonomy, beneficence and nonmaleficence. She gives a balanced 